\title{
An ATTITUDE Study on the Conflict between Mother and Her Daughter-in-law in the Novel Double-Sided Adhesive from Appraisal Theory Perspective
}

\author{
Yake Li \\ School of Foreign Languages, Beijing Forestry University, 35 Qinghua East Road, Haidian District, Beijing, China \\ Yueqin Gao \\ School of Foreign Languages, Beijing Forestry University, 35 Qinghua East Road, Haidian District, Beijing, China
}

\begin{abstract}
Appraisal Theory is promising and applicable in many fields, but its interpretation in the field of conflict discourse is still in the exploratory stage. This article, aims to analyze the attitudinal meanings of conflict discourse between Mother-in-law and Daughter-in-law in the Chinese novel Double-Sides Adhesive, so as to testify the feasibility of Appraisal Theory.
\end{abstract}

Index Terms — appraisal theory, ATTITUDE system, conflict discourse

\section{INTRODUCTION}

Since its inception in the early 20th century, Appraisal Theory has been promising and applicable in many aspects. In recent years, many Chinese scholars have conducted effective researches. Some focuses on theoretical level, intending to perfect the system $(\mathrm{Li}, 2004$; Wang \& $\mathrm{Lu}, 2010 ; \mathrm{Li}, 2006)$ while some applied the theory into translation studies (Su, 2008), Foreign Language Teaching (Liao Chuanfeng, 2008) and discourse analysis, involving novel interpretation, book reviews, stylistic analysis of news, editorial and academic discourse and other different types of discourse (Liu \& Han, 2004; Lan, 2011; Chen, 2007). However, there are few scholars utilizing Appraisal Theory to analyze conflict discourse. This paper, based on Appraisal Theory, intends to examine the attitudinal meanings in conflict discourse between mother and daughter-in-law in the Chinese novel Double-Sides Adhesive, so as to testify the explanatory power of Appraisal Theory.

\section{THEORETICAL FRAMEWORK}

Appraisal Theory, proposed by J.R.James, has expanded the study of interpersonal meaning into a new stage, from lexical-grammatical oriented to semantic oriented. Scholars of Appraisal Theory are interested in exploring what resources or choices writers or speakers have adopted to take stance towards certain people, things or phenomena, to construct textual authorities in different types of discourse, to express and negotiate positioning and attitude and to manage interpersonal relationship either align or disalign with others. In terms of the types of resources, Appraisal Theory can be divided into three subsystems: Attitude, Engagement, and Graduation (Martin \& White, 2005). Attitude is the core of appraise, which will be given detailed explanation later. Engagement refers to the source of Attitude, revealing the relationship between the writer/speaker and text/utterance and Graduation demonstrates the strength of Attitude, which is a graded system concerned with force or focus. All the three systems can be further subdivided into more sophisticated categories.

Attitude involves the resources by which writers/speakers use to express emotional responses towards participants, phenomena and processes, to judge human behavior, or to appreciate objects. As indicated by its definition, it includes three categories: Affect, Judgment and Appreciation. Affect, the core of the Attitude system, being either negative or positive, reflects the emotional responses and evaluation. Judgment explains the value that indicates how the appraiser, by reference to certain social norms and conventions or system of values, constructs judgment toward human behavior or activities. However, it should be noticed that Judgment towards the same behavior may differ as context of culture and ideological value changes (Martin \& White, 2005). Accordingly, the judging reference used in this paper will be examined under Chinese cultural background. Additionally, Judgment is very sensitive to the writer/speaker's institutional position (Martin, 2000). Lastly, being different from the previous systems, Appreciation is thing-oriented, involving the resources adopted to assess objects, processes and natural phenomena especially in aesthetic level.

\section{RESEARCH DESIGN}




\section{A. Conflict Discourse between Mother and Daughter-in-law}

Folger (2001) believes conflict is a kind of interaction between interdependent individual who may perceive incompatible goals, which leads to interference in achieving those purposes while Ran (2010) states that conflict equals to the contradiction or disputes between individuals or groups resulting from different opinions, interests, principles or purposes. As indicated in its name, conflict discourse refers to conflict in verbal communication. Zhao (2004) summarizes that when different communication parties hold different views towards words and deeds or behaviors, verbal discourse will emerge. In summary, the author tends to consider conflict discourse as the verbal conflict of individuals whose perceptions differ.

Previous scholars have explored conflict in many fields. Some focused on cross-cultural communication (Heath, 1983; Emihovich, 1986). Some examined the issue within cultural group (Edstrom, 2004; Ruzickova, 2007). Some conducted the study in cross-gender fields (Goodwin, 1990; Tanen, 1990; Kakava, 1994; Farris, 2000). Some studied under a family background (Boxer, 2002). Although many studies concerning conflict discourse have been conducted, the study on conflict discourse between mother and daughter-in-law (hereinafter referred to as CDMD) is rare.

Mother and daughter-in-law are not connected by the ties of blood but are relatives by law. They come from different families with different lifestyle or even different social status. Consequently, they hold different values and opinions; when brought into live in one family, the differences will definitely cause disagreement and conflict, making the relationship between mother and daughter-in-law much more subtle and complicated than any communications between other family members.

\section{B. Methodology}

In this study, both quantitative and qualitative approaches are involved. Firstly, based on the definition of conflict discourse, the corresponding materials concerning CDMD in the novel are identified. Secondly, Annotool is used to tag all the Attitude resources and AntConc is utilized to collect the statistical data of the appraisal values, including the frequency of each subtype resources in Judgment and Appreciation system and the distribution of negative and positive Affect in Affect system. Lastly, data tables for each system are drawn out. After all the quantitative work, qualitative analyses will be adopted to explore how mother and daughter-in-law take stances or express feeling and how they try to align themselves with each other.

\section{Analyses of Attitude Resources}

The Attitude resources in CDMD reflect both parties' emotional reactions, judgments and evaluations. And the Attitude usages will be explained and analyzed successively.

TABLE 1:

\begin{tabular}{lllll}
\multicolumn{5}{c}{ DISTRIBUTIONS OF AFFEC, JUDGMENT AND APPRECIATION IN THE SAMPLE TEXT } \\
\hline & Affect & Judgment & Appreciation & \\
Frequency & 74 & 70 & 31 & 175 \\
Percentage & $42.29 \%$ & $40.00 \%$ & $17.71 \%$ & $100.00 \%$ \\
\hline
\end{tabular}

As is shown in Table 1, compared with Appreciation, Affect and Judgment are used more frequently, which indicates that people care more about expressing emotions and judging human performances rather than appreciating objects. This can be firstly interpreted from the nature of conflict discourse: since conflict discourse is a concentrated way for speakers to demonstrate their attitude and feelings, it seems natural that there are abundant Affect resources in CDMD. As for the substantial use of Judgment resources, we can refer to the binary power fight in CDMD. In CDMD, mothers and daughter-in-laws are struggling for the ruling power in house (Chen, 2011). As a way to show their authority, they will evaluate or criticize the other party's behaviors or thoughts. Sometimes they may even try to change the opponents' ideas by making evaluations that they believed to be truthful, reliable and insightful hoping that an alignment will be reached in the end. Lastly, for Appreciation resources, since CDMD mainly occurs in daily occasions where trivialities in life are often put into discussion, there has little expressions concerning aesthetics appreciation, which makes Appreciation the least used resource in CDMD's Attitude system.

\section{1) Affect Analyses}

According to the present study, we find that Affect is of the highest percentage among all attitudinal resources and the frequency of positive and negative Affect is shown in the following table:

TABLE 2:

DisTRIBUTIONS OF POSITIVE AND NEGATIVE AFFECT IN THE SAMPLE TEXT

\begin{tabular}{llll}
\hline & Positive & Negative & Total \\
Frequency & 3 & 71 & 74 \\
Percentage & $4.05 \%$ & $95.95 \%$ & $100.00 \%$ \\
\hline
\end{tabular}

From table 2, we can see that negative Affect dominates in CDMD while positive Affect only takes a small part of it. The large amount of negative Affect directly reflects the negative feelings caused by the conflict between mother and daughter-in-law. These negative Affect is not only a reflection of a powerful emotional outpouring, but also a strategy for both parties to establish a psychological alliance. Meanwhile, it is necessary since both mother and daughter-in-law 
want to declare their authority in the house. This can be elaborated by the following example (Affect is in bold, positive Affect is token as [+] while negative one as [-], similarly hereinafter)

Li Juan (the wife) trooped down stairs and slapped Yaping (the husband) just in front of Yaping's mother. The mother-in-law shouted immediately: "How dare you?! Based on what (ping shen me) [-]? Can't you cool down and have a talk?" Contemptuously, Lijuan lazily replied: "It is I spoke with my husband and it is I educate my husband. It's my husband. Ok? It's none of your business (guan ni pi shi)?” [-]

In the above case, the mother-in-law expresses her dissatisfaction to the daughter-in-law by questioning "based on what (ping shen me)", and the daughter-in-law shows her dissatisfaction and despise by saying "none of your business (guan ni pi shi)". Both parties have directly shown their dislikes. Dislike and hatred of both parties have been highlighted to accentuate the intensity of conflict and the fierceness of emotional clash.

Moreover, the usage of Affect can foreground feelings, making the listener easier to identify with the speaker, thus achieving the effect of "touching someone by emotions". Consider the following examples.

1. "(mortgage) makes people feel uncomfortable (bu shu tan) [-] ... If I were you, I would even turn into sleepless (shi mian) [-] at night."

2. "You see, we've suffered so much misfortunes, as a mother I feel terribly sorry (dui bu qi) [-]. I own your family an apology (dao qian). [-]...Making your mother end up in the hospital, I was also having a hard time (bu hao shou)[-] myself..." Sitting on the couch, Yaping' mother bowed deeply to Lijuan as showing sincere apology.

In case 1, the Mother-in-law makes her assessment for the mortgage. She applies the negative Affect resource "uncomfortable (bu shu tan)" to force the daughter-in-law to agree with her and to make the listener establish an emotional association between mortgage, unhappiness and insecurity. She tries to pressure the other party emotionally, thus teaching the daughter-in-law to be an economical housekeeper in the future. In case 2, she wants to resolve the conflict between two families and be forgiven by Lijuan. Therefore, she expresses her guilty, sadness and other negative Affect resources, not only demonstrating her genuine apology but also creating a sincere atmosphere to gain emotional recognition so that she can be forgiven by her daughter-in-law.

Lastly, it is worth noticing that the conflict discourse between mother and daughter-in-law are usually for them to stress their authorities: the mother-in-law emphasizes her identity of being the mother of the male master in the house while the daughter-in-law often highlights her identity as the female master of the house. Therefore, during verbal conflicts, they often highlight their rights by questioning, warning, commanding and other types of speech, which contain a lot of negative Affect resources. More examples will be provided to illustrate the point:

3. Lijuan answered with a lazy voice: "If you want to live in my house, you must get along with my rules. My rules or go out (gun) [-], you choose, because I've ran out of patience kissing your ass (bu ai ci hou)[-]."

4. Li Juan looked contemptuously at her mother-in-law and said: "It's none of your business (guan ni pi shi) just get out of my way (shan kai)! [-]Shape up or get out (gun dan)! [-] ... As I told you, this is my house, my home, and it is my family who paid for the money... and if you dare to ruffle (bu shuang kuai)[-] me, I could kick you all out (yi kuai gun)[-], even with this man here!" Yelling at the mother-in-law, Lijuan angrily gave Yaping another slap in the face.

In case 3, Lijuan declares her power against the mother-in-law as the female master in the house. The usage of "get out (gun)" and "I ran out of patience kissing your ass (bu ai ci hou)" completely denounces her mother-in-law, which has highlighted her dominance in the family over the mother-in-law; while in case 4, Lijuan scolds her mother-in-law with the expression of "none of your business (guan ni pi shi)" so as to weaken the mother-son relationship between her mother-in-law and her husband, thus underlining her control over her husband. Meanwhile, in order to further cement her identity of being the female master in the house, she warns the other party not to "ruffle (bu shuang kuai)" her, otherwise she could "kick you all out (yi kuai gun)". In all, Lijuan tries to apply these Negative Affect to claim her status of being the wife and the female master to win the binary fight for power between herself and her mother-in-law.

\section{2) Judgment Analyses}

The system of Judgment can be subdivided into Social Esteem and Social Sanction. Social Esteem concerns the evaluation of people's behaviors based on the conventions of a community, indicating whether the esteem or status of the appraised is enhanced or degraded (Liu \& Han, 2004). But Social Sanction often concerns the judgment of being right or wrong, involving legal implications as well as moral principles. As mentioned above, standards of Judgment can be sensitive to individual's ideology, that is, what can be viewed as appropriate and favorable by one individual may turn out to be weird and dissatisfactory for another individual. Whether the listener can accept and recognize the value the speaker advocates is essential for winning over a conflict discourse.

TABLE 3:

DISTRIBUTIONS OF JUDGMENT IN THE SAMPLE TEXT

\begin{tabular}{|c|c|c|c|c|c|}
\hline \multicolumn{6}{|c|}{ IIONS OF JUDGMENT } \\
\hline & Positive Judgment & Negative Judgment & Social Sanction & Social Esteem & Total \\
\hline Frequency & 18 & 52 & 58 & 12 & 70 \\
\hline Percentage & $25.71 \%$ & $74.29 \%$ & $82.86 \%$ & $17.14 \%$ & $100.00 \%$ \\
\hline
\end{tabular}

From table 3 we can see that the Negative Judgment dominates over Positive Judgment and in terms of subtypes of Judgment, most are Social Sanction, especially concerning the "appropriateness" of behaviors (In all 47 examples we collected in the sample text, negative ones contributing 36), which demonstrates appraiser's disapproval of the behavior or thoughts of the appraised. This can be traced back to the causes of CDMD: for example, the generation gap, 
differences in value systems, education background or other aspects the two parties perceive differently, thus making Negative Judgment on the other party and may even try to overthrow the other party's visions and concepts and establishes a set of new value for each other (Chen, 2011). This can be demonstrated in the following example (The Judgment resources are all Social Sanction resources tagged in bold. Therefore, they are not marked one by one. Positive Social Sanction is token as [+] while negative one as [-], similarly hereinafter):

1. Yaping's mother was not happy. When having dinner, she constantly refilled Lijuan's bowl and coldly said: "For God's sake, eat, ok? You are slim enough. There's no need for you to lose weight. You can resist hunger, but not your child! I thought that mothers care their own child more than everything, as long as the child is healthy, little fat would not be harm, I didn't expect that someone could be so cruel (can ren)[-]to her own child." Upon hearing this, Li Juan got angry: "I was talking to my mom to comfort her. Who would know that some could hold her ears that high (shui zhi dao you ren er duo zhe me chang) [-] ... and only enjoyed setting people at loggerheads (tiao bo zhao cha)[-]? ..."

In the above example, mother-in-law ironically criticizes Lijuan because Lijuan is not willing to eat. Mother-in-law does not approve of that since Lijuan is pregnant and should eat for the child's sake. Upon hearing mother-in-law's criticism, Lijuan gets angry so she uses rhetorical questions and Negative Judgment resources to strongly declare her opposition against her mother-in-law: the question of "Who would know that some could hold her ears that high (shui zhi dao you ren er duo zhe me chang)" is to denounce the shameful behavior of the mother-in-law's eavesdropping while the usage of "setting people at loggerheads (tiao bo zhao cha)" is to criticize the behavior of setting the couple apart purposely.

Besides, due to the reason that Judgment can help the speaker to build up attitude and define the cultural ideology and values, the application of Judgment resources can achieve the goal of persuasion and values-sharing. Please refer to the examples quoted below:

2. 'It's not about the money, we can't afford to waste (lang fei)[-]! You haven't experienced the tough times yet so you can never imagine what life goes on back in the 60s. Even one penny can be accumulated into one hundred, if you start to save (sheng yi fen shi yi fen bu shi) [+]."

3. "Mama, if all the people were like you, there would be no social progress and all the factories would be closed down. No wonder you plant has been closed. It is the people like you that have hindered our country's development (tuo she hui zhu yi hou tui)[-]. You should establish the concept of consumption (yao shu li xiao fei guan nian)[-], make more and spend more...things changes so greatly every day, you should keep up with the times (yao gen shang shi dai)[-]!"

In the example above, mother-in-law, surviving from the hard times, knows well the difficulties and hardship in life. She believes in frugality and thrift as observed in the traditional families. Therefore, she is against wasting but advocates saving. She wants the daughter-in-law to share the consuming value of being thrift and frugal with her. Contrarily, the daughter-in-law, being educated by modern value, advocates realizing individual consuming potential, therefore, she believes that frugality is "hindering (tuo hou tui)" the progress of society and is improper. She uses two "should (yao)", indicating that the mother-in-law should accept the modern consumption value.

\section{1) Appreciation Analyses}

Appreciation deals with "resources for construing the value of things, including natural phenomena and semiosis (as either product or process)" (Martin \& White, 2005, p.36). It can be subdivided into 3 categories: Reaction, Composition and Valuation. Reaction reflects the degree to which the text/process attracts us, and the degree to which its emotional impact has on us. Composition deals with people's perceptions of proportionality and complexity. Valuation demonstrates our assessment of the social or aesthetic significance of the appraised.

TABLE 4:

DISTRIBUTIONS OF APPRECIATION IN THE SAMPLE TEXT

\begin{tabular}{lllll}
\hline & Reaction & Composition & Valuation & Total \\
Frequency & 7 & 3 & 21 & 31 \\
Percentage & $22.58 \%$ & $9.68 \%$ & $67.74 \%$ & $100.00 \%$ \\
\hline
\end{tabular}

From Table 4, we can find that Valuation takes a large proportion in the Appreciation system in CDMD. This indicates that most Appreciation is related with the values of the appraised, either on aesthetic level or on social level. These evaluations, when concerning aesthetically, can reflect different aesthetic orientations of both parties; when construing social values, different value systems can be adopted. This reveals that the cultural and group differences reflected by aesthetics and social values are one of the important reasons for CDMD. This can be seen in the following example (Appreciation resources are in bold, with positive one tagged as [+] and negative one as[-]):

1. "Mom, isn't it a nice (hao kan) [Reaction +] shirt?" Lijuan asked her mother-in-law. "There is one in his closet just like this one (cha bu duo) [Valuation -], that is blue, no difference to this one, just the color (hao xiang jiu yan se bu yi yang) [Valuation -]." "They are absolutely different (bu yi yang)! [Valuation +] that one is last year' trend (qu nian de kuan shi) [Valuation -] and has a small lapel. But this year people favors collarless shirts just like this one, a imitation from Richard Gere's movie, and also this one is white, it really looks good (shuai)[Reaction +]on your son!"

"It's just a lapel! (bu jiu shi ge ling zi ma)[Valuation -] clothes are just to keep us warm, you'll never catch up with the trendy styles. Look at my sweater. I bought it ten years ago. It is still as good as a new one (yi dian bu luo hou)! [Valuation, +]." 
As shown in the above example, mother-in-law and daughter-in-law express different views on Lijuan's newly bought clothes. Lijuan likes wearing trendy clothes and believes the latest styles are better-looking; while the mother-in-law views that there is no difference between new styles and outdated styles, only durability counts, so there is no need to spend too much money on buying new clothes. The Appreciation resources applied by both parties not only reflect different aesthetics but also different consumption values, revealing the origin of disapprovals.

\section{CONCLUSION}

Based on the Chinese novel the Double-Sided Adhesive, it is discovered that in CDMD, the attitudinal meanings are more frequently reflected by the use of Affect and Judgment. This shows that the speakers concern more about the affective domain and the evaluation of human behavior in the material world. In Affect system, negative resources overweight positive ones, which not only indicates an emotional outpouring but also facilitates the establishment of psychological alliance, as well as the declaration of authority. In Judgment system, the negative assessment, especially the Judgment in terms of Social Sanction contributes a majority, which is closely related to the causes of CDMD. Due to both cultural and ideological differences, when a mother and a daughter-in-law live together, conflicts occur, leading to negative evaluations on each other's behaviors and thoughts. This demonstrates the common purpose of both, that is to try to change the other party culturally or ideologically, thus more Judgment resources are adopted in order to achieve evaluative purpose and persuasion. In Appreciation system, the proportion of Valuation resources is quite large, serving as an indication that the different thoughts on aesthetics and social values are also one of the reasons for CDMD.

In summary, this study helps deepen the understanding of CDMD and validate the feasibility of Appraisal Theory in this field, expanding its scope of application. But it should be noted that Appraisal Theory is not fully applicable to the Chinese discourse, especially the evaluation criteria for Judgment system. Systematized and standardized explorations concerning with the improvement of Appraisal Theory in a Chinese Context are urgently needed.

\section{REFERENCES}

[1] Anne Edstrom. (2004). Expressions of disagreement by venezuelans in conversation: reconsidering the influence of culture, Journal of Pragmatics, 8, 1499-1518.

[2] Catherine Emihovich. (1986).Argument as status assertion: contextual variations in children's disputes. Language in Society, 15, 485-500.

[3] Catherine S.P. Farris. (2000). Cross-sex conflict and the discursive production of gender in a Chinese preschool in Taiwan, Journal of Pragmatics, 5, 539-568.

[4] Chuanfeng Liao. (2008). Appraisal theory and teaching of fl reading__ a new approach to revealing the theme of a text, Foreign Language Education, 4, 47-50.

[5] Deborah Tannen. (1990). You Just Don't Understand: Women and Men in Conversation. New York: William Morrow.

[6] Diana Boxer. (2002). Nagging: the familial conflict arena, Journal of Pragmatics, 34, 49-61.

[7] Elena Ruzickova. (2007). Strong and mild requestive hints and positive-face redress in cuban Spanish, Journal of Pragmatics, 6 , 1170-1202.

[8] Fagen Li. (2006). Recognization, functions and parameters of evaluation, Foreign Languages and Their Teaching, 11, 1-3.

[9] Fudan Chen. (2011). The preliminary study of the relationship between mother and daughter-in-law in china, Science of Social Psychology, 9, 55-57.

[10] James. R. Martin. (2000). Beyond exchange: appraisal systems in English, in S. Hunston and G. Thompson (eds.), Evaluation in Text: Authorial Stance and the Construction of Discourse. Oxford: OUP, 142-175.

[11] James. R. Martin and Peter White. (2005). The Language of Evaluation-Appraisal in English. NewYork: Palgrave Macmillan.

[12] Joseph P. Folger and Randall. K. Stutman. (2001). Working Through Conflict: Strategies for Relationships, Groups, and Organizations. New York: Longman.

[13] Kakava, C. (1994). "Do you want arguments with to get engaged, baby?": the cultural construction of gender through talk, in Bucholtz (eds.), Cultural Performances. Berkeley: Berkeley Woman and Language Group, 344-354.

[14] Rongjuan Li. (2005). The attitudinal meanings of English column texts-from the perspective of appraisal theory, Shandong Foreign Languages Teaching Journal, 4, 30-33.

[15] Shirley Brice Heath. (1983). Ways with Words: Language, Life and Work in Communities and Classrooms. Cambridge: Cambridge University Press.

[16] Shizhu Liu and Jinlong Han. (2004). Appraisal system in news discourse, Media in Foreign Language Instruction, 4, 17-21.

[17] Xiaoyan Chen. (2007). A contrastive analysis of attitudinal realization in English and Chinese editorials, Journal of Foreign Languages, 3, 39-46.

[18] Xiaoyu Lai. (2012). A pragmatic study of intentional impoliteness in the conflict between a mother-in-law and her daughter-in-law, Journal of Guangdong University of Foreign Studies, 2, 37-41.

[19] Xiaoyan Lan. (2011). Evaluation strategies in English academic book reviews-an attitude analysis from the appraisal theory perspective, Shandong Foreign Language Teaching Journal, 2, 13-20.

[20] Yingling Zhao. (2004). Conflict talk analysis, Foreign Language Research, 5, 37-42.

[21] Yihua Su. (2008). Meaning equivalence vs. attitude difference in translation, Foreign Language Research, 5, 100-102.

[22] Yongping Ran. (2010). A survey of the pragmatics studies of conflict talk, Foreign Language Education, 1, 1-6.

[23] Zhanzi Li. (2004). Appraisal theory: applications and problems in discourse analysis, Foreign Languages Research, 5, 1-6.

[24] Zhenhua Wang \& Yang Lu. (2010). A reflection on engagement systems, Foreign Language Research, 3, 51-56. 
Yake Li was born in Hunan, China in 1989. She received her B. A. Degree in English from Beijing Forestry University, China in 2007.

She is currently a graduate student in the School of Foreign Language, Beijing Forestry University, Beijing, China. Her research interests include cognitive linguistics and second language acquisition.

Yueqin Gao was born in Beijing, China in 1969. She received her M.A. degree in linguistics from Beijing University of Aeronautics and Astronautics, China in 2001.

She is currently an associate professor in the School of Foreign Languages, Beijing Forestry University, Beijing, China. Her research interests include sociolinguistic, pragmatics and cognitive linguistics. 